\title{
REVISTA CAROS AMIGOS E MANIFESTAÇÕES DE JUNHO 2013: UMA ANÁLISE ÉTICO-POLÍTICA
}

\author{
THE MAGAZINE CAROS AMIGOS AND \\ MANIFESTATIONS OF JUNE 2013: AN ETHICAL \\ AND POLITICAL ANALYSIS
}

\author{
Leide Dayana Caetano ${ }^{1}$ \\ Rita de Cássia Gabrielli Souza Lima ${ }^{2}$
}

RESUMO: Este artigo apresenta parte dos resultados de pesquisa de mestrado sobre as reivindicações populares expressas nas manifestações de junho de 2013. Pesquisa documental, realizada na versão on-line da Revista Caros Amigos, com recorte temporal entre 01/06/2016 e 31/10/2016. A análise ético-política das notícias foi conduzida por meio da categoria "De Saúde como Direito Social à Democracia como Direito à Saúde". A partir das relações com os dados, foi possível concluir que as manifestações geraram desdobramentos em matéria de direitos sociais. O Plano Nacional de Educação foi instituído com metas para até 2024. O Programa Mais Médicos foi criado, garantindo atenção médica na atenção básica do SUS de Brasis desassistidos. A produção e a difusão de saberes e reconhecimentos populares produziram uma tecnologia social, pois viabilizaram os anseios de uma população que historicamente luta por seus direitos e busca a cada dia, em meio à opressão e ao sofrimento, fazer com que suas vozes sejam ouvidas e seus anseios atendidos nesta democracia representativa sem representatividade. Ainda assim, fica a compreensão de que o Brasil requer um choque de cidadania, para que possa defender um projeto justo de sociedade.

PALAVRAS-CHAVE: Democracia; Direitos Sociais; Direito à Saúde; Tecnologia Social.

ABSTRACT: This article presents some of the findings of a Master's degree study of popular demands expressed in the manifestations of June 2013. It is document-based study conducted on the online version of Caros Amigos Magazine, with a time cut-off of June 1st to October 31st, 2016. The ethical and political analysis of the news was conducted based on the category "About Health as a Social Right to Democracy as a Right to Health". The relations with the data led to the conclusion that the manifestations have generated further developments regarding social rights. The National Education Plan has been instituted with targets for to 2024. The More Medical Doctors Program was designed to guarantee medical assistance within the SUS primary health care of unassisted Brazilian areas. The production and dissemination of knowledge and popular recognitions have produced a social technology, as they facilitate the wishes of a population that has historically struggled for its rights, and that attempts, every day, amidst oppression and suffering, to have its voices heard and its wishes met in this representative democracy with no representativeness. Yet, the understanding remains

Licença CC BY:

Artigo distribuído sob os termos Creative Commons, permite uso e distribuição irrestrita em qualquer meio desde que o autor credite a fonte original. that Brazil requires a citizenship shock so that it can defend a fair society project.

KEYWORDS: Democracy; Social Rights; Right to Health; Social Technology.

1 Enfermeira. Especialista em Processo de Trabalho em Redes. Mestranda em Saúde e Gestão do Trabalho pela Universidade do Vale do Itajaí - UNIVALI.

2 Dentista. Doutora em Saúde Coletiva e Mestre em Saúde Pública pela Universidade Federal de Santa Catarina - UFSC. Professora titular da UNIVALI.E-mail: rita.lima@univali.br. 


\section{INTRODUÇÃO}

As jornadas de junho de 2013 protagonizaram várias manifestações populares sobre a crise de representação político-democrática no Brasil (LINCOLN et al., 2013). Vozes soberanas das ruas expuseram históricas feridas, geradas pelos complexos mecanismos de desenvolvimento das sociedades: frustrações, inquietações e insatisfações das mais diversas origens foram externadas naquele momento histórico. Do vazio de representação política, passando pela indignação com investimentos em grandes obras (como as dos estádios para a copa de 2014) ao clamor por garantia de serviços públicos, de saúde, educação, mobilidade pública, transporte, segurança, dentre outros (GONÇALVES, 2013).

As manifestações corresponderam ao reflexo de frações de classes de uma juventude posicionada à margem do Estado de Direito, sobretudo no que se refere à garantia de direitos sociais, negligenciada há décadas (BOITO JÚNIOR, 2016).

Deflagrados pelo Movimento Passe Livre (MPL), em função do aumento das tarifas de transporte ocorrido na conjuntura da época, os fatos desdobraram-se em dois momentos: a) o primeiro, popular(BOITO JÚNIOR, 2016), forjado por jovens da baixa classe média e trabalhadores que, após qualificação profissional incentivada pela expansão do ensino superior, oportunizada pelo governo federal, se depararam com restrito mercado de trabalho (POCHMANN, 2012) e, ainda, com o vazio de garantia de direitos sociais, conquistados em 1988 (GONÇALVES, 2013); b) o segundo, a massificação dos movimentos e a expansão para as diversas cidades e regiões do país, ficando as mesmas tomadas por "vozes inconformadas com a sombria realidade social" (SCHERER-WARREN, 2014, p.419), concomitante à incorporação da alta classe média e seu genérico discurso de corrupção (BOITO JÚNIOR, 2016).

Embora as manifestações tenham sido deflagradas pelo MPL, em contraposição ao aumento das tarifas de ônibus, o núcleo central delas foi o descaso da democracia representativa brasileira, frente à sua incapacidade de garantir os direitos sociais, bem como o repúdio à corrupção nas instituições nacionais (COMPARATO, 2016). Neste sentido, os movimentos sociais de 2013 realizaram o papel histórico de revelar as tensões e as contradições sociais do momento histórico, impostas pela formação econômica e social brasileira, na medida em que nesta estrutura os direitos sociais estão subsumidos ao projeto macroeconômico.

Na última semana daquele junho histórico, o governo federal anunciava o delineamento de um programa voltado para a garantia do direito à saúde na atenção básica do Sistema Único de Saúde (SUS), na especificidade da atenção médica. Em uma reunião com ministros, governos estaduais e alguns governos municipais, a presidenta Dilma Rousseff socializou que este programa estaria dirigido para a fixação de médicos em áreas remotas, cidades do interior e periferia de grandes centros, mediante a oferta de curso de especialização na atenção básica, bolsa-formação e ajuda de custo (BRASIL, 2013a). Em julho, o governo criou o Programa Mais Médicos, por meio de uma medida provisória (BRASIL, 2013b). Três meses depois, esta medida foi regulamentada pela Lei 12.871/2013 (BRASIL, 2013c).

Este artigo apresenta os resultados de uma pesquisa de mestrado realizada sobre a cobertura das manifestações de junho de 2013, a partir de notícias veiculadas pela Revista Caros Amigos, no período entre 01/06/2013 e 31/10/2013. O objetivo foi analisar os elementos reivindicatórios em defesa do Sistema Único de Saúde, expressos em tais manifestações. 


\section{METODOLOGIA}

Estudo documental derivado da pesquisa "Impacto Social do Programa Mais Médicos em Santa Catarina: realidades e perspectivas”, executada com financiamento da Fundação de Amparo à Pesquisa e Inovação do Estado de Santa Catarina (FAPESC) e apoio direito da Secretaria de Estado da Saúde (SES/SC). Foi aprovado pelo CEP/UNIVALI, sob o número 1.358.561, e executado em conformidade com as determinações da Resolução CNS 466/2012/CNS/MS/CONEP.

O estudo teve a mídia como fonte de dados. Esta modalidade de pesquisa permite o encontro indireto com produções humanas (PIMENTEL, 2001) e tem como particularidade a natureza primária das fontes (SPINK, 2014).

Como um campo difusor de informação, a mídia tem sido reconhecida pela sua influência na produção e na reprodução de valores e sentidos, seja pela introdução de temáticas como pela introdução de diversas formas de abordagem de uma dada temática. Esta compreensão é importante, pois o tipo de documento por ela produzido proporciona novas configurações de produção de sentidos. Tais documentos, ao serem publicados e postos em circulação, tornam-se acessíveis e, consequentemente, abertos a leituras e releituras, interpretações e questionamentos (SPINK, 2013).

Em pesquisa documental com mídia, tem que se ressaltar a necessidade de atenção cuidadosa com o tipo de versão, se impressa ou on-line, sem a qual a credibilidade da pesquisa pode ser questionada (SPINK, 2013).

Nesta pesquisa, utilizou-se a versão on-line da Revista Caros Amigos. Na composição do corpus de análise, foram considerados textos noticiados pelo arquivo privado, de domínio público, acerca das manifestações ocorridas em 2013, publicadas no período entre 01/06/2013 e 31/10/2013. Este recorte temporal da pesquisa foi eleito em virtude de a mídia brasileira ter realizado, neste período, uma ampla cobertura das manifestações.

A Revista Caros Amigos foi gestada por um grupo de amigos, que incluiu jornalistas, publicitários, profissionais liberais e profissionais da comunicação. Em encontros informais, ocorridos na década de 1990, sob a liderança de Sérgio de Souza, eles passaram a discutir sobre como criar um veículo contra-hegemônico, mais questionador, crítico, progressista e independente; como recuperar textos de qualidade, uma exigência do momento histórico. Com essa finalidade, a Revista foi lançada em abril de 1997 e, desde então, tem distribuição mensal e caracteriza-se por suas matérias reflexivo-críticas (SIMIELLI, 1997).

A coleta de dados foi realizada no site on-line da Revista Caros Amigos. A utilização do descritor "Manifestações de Junho de 2013" gerou 14 (quatorze) notícias. Como critério de inclusão, consideraram-se reportagens que contemplavam reivindicações em defesa do SUS. Os critérios de exclusão foram: a) matérias de cunho político-partidário e b) matérias publicadas no recorte do estudo sobre outras manifestações, que não as de junho de 2013.

As 14 (quatorze) notícias foram transcritas para o Word e colocadas em ordem por data de publicação. Para fins de sistematização, optou-se por representar os textos pela sigla NCA (Notícias Caros Amigos), seguida por um ordenamento numérico (Quadro 1). Uma vez concluído o processo de tabulação dos dados, iniciou-se a exploração do material. As notícias foram lidas várias vezes, com a devida compreensão de esta fase requerer o mergulho nos dados de modo distanciado da dimensão interpretativa, visando conhecê-las originalmente. Após sucessivas leituras exploratórias, foram realizadas novas leituras, já analíticas, para fins de seleção de unidades 
de registro com equivalência de subcategorias, progressivamente agrupadas na categoria "Da saúde como direito social à democracia como direito à saúde”.

O método de análise foi ético-político, tomando por base a dimensão reflexivo-crítica para compreender "o modo de" (LIMA et al., 2016), isto é, o modo como o campo 'em defesa do SUS' se relacionou com as manifestações veiculadas. Este método é derivado do método humanístico de análise da realidade, denominado do "posto que", capitaneado por Antonio Gramsci, em que a realidade, sempre histórica, dialoga com suas inclinações contraditórias (MANACORDA, 2012, p.39).

Quadro 01: Descrição das notícias de acordo com data de veiculação e autoria.

\begin{tabular}{|c|c|c|c|}
\hline Revista & Título & $\begin{array}{l}\text { Data da } \\
\text { Publicação }\end{array}$ & $\begin{array}{l}\text { Autor/Responsáveis } \\
\text { pela publicação }\end{array}$ \\
\hline $\begin{array}{l}\text { Caros } \\
\text { Amigos }\end{array}$ & Proclamações perigosas & 03/06/13 & $\begin{array}{l}\text { Fábio Py Murta De } \\
\text { Almeida }\end{array}$ \\
\hline $\begin{array}{l}\text { Caros } \\
\text { Amigos }\end{array}$ & Manifesto contra violência policial em SP & $14 / 06 / 13$ & Movimentos Sociais \\
\hline $\begin{array}{l}\text { Caros } \\
\text { Amigos }\end{array}$ & A tarefa é fortalecer as lutas sociais & $14 / 06 / 13$ & Por Redação \\
\hline $\begin{array}{l}\text { Caros } \\
\text { Amigos }\end{array}$ & A tivismo: o movimento acéfalo das manifestações & $24 / 07 / 13$ & $\begin{array}{l}\text { Fábio Py Murta De } \\
\text { Almeida }\end{array}$ \\
\hline $\begin{array}{l}\text { Caros } \\
\text { Amigos }\end{array}$ & $\begin{array}{l}\text { Ouvir de fato as ruas: a falta de Euclides da Cunha } \\
\text { na mídia }\end{array}$ & $07 / 08 / 13$ & $\begin{array}{l}\text { Rogério Lustosa } \\
\text { Bastos }\end{array}$ \\
\hline $\begin{array}{l}\text { Caros } \\
\text { Amigos }\end{array}$ & Livro reúne artigos sobre os protestos de junho & $09 / 08 / 13$ & Por Redação \\
\hline $\begin{array}{l}\text { Caros } \\
\text { Amigos }\end{array}$ & $\begin{array}{l}\text { MPL move ação contra governo de SP por abuso } \\
\text { de poder da PM durante protestos }\end{array}$ & $29 / 08 / 13$ & Por Brasil De Fato \\
\hline $\begin{array}{l}\text { Caros } \\
\text { Amigos }\end{array}$ & Globo: o odor da saturação & $02 / 09 / 13$ & Por Saul Leblon \\
\hline $\begin{array}{l}\text { Caros } \\
\text { Amigos }\end{array}$ & Truculência policial no Rio de Janeiro & $13 / 09 / 13$ & Por Leandro Uchoas \\
\hline $\begin{array}{l}\text { Caros } \\
\text { Amigos }\end{array}$ & Marilena Chauí: o efeito das manifestações & $13 / 09 / 13$ & $\begin{array}{l}\text { Por Aray Nabuco et } \\
\text { al. }\end{array}$ \\
\hline $\begin{array}{l}\text { Caros } \\
\text { Amigos }\end{array}$ & O fim do partido? & 20/09/13 & José Arbex Jr. \\
\hline $\begin{array}{l}\text { Caros } \\
\text { Amigos }\end{array}$ & $\begin{array}{l}\text { Licitação do transporte: o problema veste a máscara } \\
\text { de solução }\end{array}$ & $15 / 10 / 13$ & MPL Florianópolis \\
\hline $\begin{array}{l}\text { Caros } \\
\text { Amigos }\end{array}$ & SP: debate discute manifestações no Brasil & $30 / 10 / 13$ & Por Redação \\
\hline $\begin{array}{l}\text { Caros } \\
\text { Amigos }\end{array}$ & $\begin{array}{l}\text { Cidade tomada: arte e diversidade nas ruas em } \\
\text { erupção }\end{array}$ & $30 / 10 / 13$ & Júlia Tavares \\
\hline
\end{tabular}

Fonte: Elaborado pela autora. 
O tratamento do material foi realizado por quatro etapas (MINAYO, 2014): a) exploração dos dados - empreendida por meio de leituras livres dos conteúdos transcritos; b) ordenação dos dados - efetuada com o auxílio de codinomes (sigla NCA, seguida de números em ordem crescente); c) classificação dos dados - desenvolvida após leituras meticulosas do material, a partir da relação entre os dados empíricos, os objetivos e os pressupostos teóricos, quando se identificaram, em núcleos de sentido, as ideias centrais: saúde, direito social, democracia; d) categorização, gerada no encontro entre as vertentes epistemológica, instrumental e reflexiva das ideias centrais: "Da saúde como Direito Social à Democracia como Direito à Saúde”.

Com base na categoria "Da Saúde como Direito Social à Democracia como Direito à Saúde”, a relação com os dados apontou que as manifestações desencadeadas por frações de classes refletiram a luta na esfera de direitos:

Organização popular pela luta por direitos" [...] (NCAO2) "Especialmente no Brasil de hoje, se as autoridades instituídas parecem negar que há os 99\% da população que têm direitos, essas manifestações são mais do que legítimas. (NCAO5).

Aproximando a citação da especificidade da saúde como direito social, os manifestantes clamaram legitimamente por respeito ao SUS conquistado, uma vez que a inversão desfavorável na correlação de forças, ocorrida após a conquista social do SUS pela VIII Conferência Nacional de Saúde, impediu a concretização de saúde como direito de todos (BRASIL, 1986). Após quase trinta anos da conquista, as manifestações expressaram o grito reprimido. A indagação que se coloca é que se basta, neste momento histórico brasileiro, o horizonte de luta por direito conquistado ou se essa luta exige expansão, em direção ao enfrentamento das iniquidades em saúde.

Ao longo da história, o Brasil tem sido palco de manifestações de reivindicação por direitos. No século XX, quase sempre as manifestações foram desencadeadas por jovens estudantes, que se organizavam nas universidades, escolas e centros comunitários, por meio de panfletos (BOITO JÚNIOR, 2016). Em uma breve análise retrospectiva dos últimos 50 anos, os movimentos sociais e as organizações populares assumiram diversas posições em relação ao Estado brasileiro. Entre os anos 60 e 70, posicionaram-se contra o Estado de exceção imposto pelos militares; nos anos 80, mobilizaram-se no sentido de pressionar a abertura política e a construção de um Estado democrático de direito, selado, em 1988, com a Constituição Cidadã. Já na década de 1990, foi a vez de barrar a instauração do Estado mínimo e a dissolução do público para os interesses do privado (SEMERARO, 2011).

Em 2013, por sua vez, elas foram organizadas maciçamente pelas redes sociais (internet), tornando possível a disseminação das informações em tempo real aos fatos (SCHERERWARREN, 2014): [...] "os protestos são realmente contra o capitalismo global [...] em defesa das liberdades civis e da democracia” (NCAO6). Esta frase parece configurar o histórico posicionamento dos movimentos sociais e das organizações populares, exposto ao longo dos anos, frente ao Estado: um posicionamento de luta, seja pela conquista, de fato, do Estado democrático e pela defesa dos direitos conquistados; seja pela defesa das liberdades civis e da democracia, gravemente ameaçadas (DE MORAES et al., 2015).

Ao longo das últimas décadas de luta, o Estado passou a ser visto não mais como uma esfera superior e externa que tinha de ser combatida e controlada, mas como um espaço a ser disputado, a ser recriado e dirigido, a partir do coletivo, em sintonia com um projeto de sociedade planejado e construído coletivamente. 
Nos últimos anos, os movimentos sociais conseguiram colocar em discussão algumas pautas importantes, tais como: a luta pela garantia de direitos sociais em políticas de Estado; a luta em defesa dos direitos humanos, direitos das minorias, contra o racismo, em defesa da comunidade LGBT; dentre outros avanços (MARICATO et al., 2013).

No entanto, as lutas e as reivindicações, manifestadas em junho de 2013, não ecoaram em ações estruturantes por parte do Estado, por exemplo, em reforma política, reforma tributária, investimentos efetivos em saúde e educação; transporte público de qualidade para todos; reurbanização das cidades. Ao contrário, no período em que esses dados foram analisados, primeiro semestre de 2016, o governo federal se distanciava da possibilidade de criar políticas estruturantes, a partir da ressignificação de suas escolhas institucionais, pois um projeto de golpe se avizinhava, consolidando-se em agosto de 2016.

Outra questão veiculada, pertinente ao objeto saúde, diz respeito à ausência do direito de livre circulação e do direito à cidade:

As altas tarifas do transporte público representam um problema social, que prejudica o conjunto da população, especialmente os mais pobres, que moram na periferia. […] há uma clara opção que privilegia o transporte privado e individual em detrimento do público e coletivo (NCAO2). [...] foi uma conjuntura de recusa, de explosão do inferno urbano [...] a explosão dos automóveis, da falta de mobilidade total, a explosão dos condominios e shoppings centers. (NCA1O).

O parágrafo anterior expressa o vazio em que estão inseridos o direito de todos de ir e vir e o de desfrutar do espaço público como um direito coletivo em face da hegemonia do transporte privado. E o direito de ir e vir e de desfrutar do espaço público são dimensões do direito à saúde. Considerando saúde como um meio para se alcançar dignidade(DINIZ, 2009), resultante das formas de organização social de produção(BRASIL, 1986), não é necessário muito esforço intelectual para compreender que a garantia de saúde requer a compreensão de ela ser uma questão da sociedade de classes. A dialética entre o transporte público e transporte privado, apontada anteriormente, é uma de suas formas de expressão.

Na perspectiva da bioética cotidiana, saúde como bem comum não se garante sem uma finalidade e meios políticos, também, comuns. A garantia de condições dignas de vida para o enfrentamento das adversidades, imposta, sobretudo, em contextos cosmopolitas, depende dos fins e meios eleitos pela política macroeconômica e políticas sociais, que se constituem no processo geral de base para a vida (digna) da sociedade (BERLINGUER, 2000). E o direito à cidade, ao transporte público e à mobilidade urbana são elementos estruturantes dessas condições. Deste modo, o direito à cidade não pode ser concebido simplesmente como um direito individual; ele demanda um esforço coletivo e a formação de direitos políticos coletivos ao redor de solidariedades sociais (DE MORAES et al., 2015).

Carlos Nelson Coutinho expõe em "O Estado brasileiro: gênese, crise, alternativas" que, do início do século XX até a década de 1980, a nação brasileira conviveu quase que constantemente com ditadura e sem hegemonia, e seu processo urbano acompanhou esse curso estatal (COUTINHO, 2007). Com a chegada do neoliberalismo, nos anos 90, a territorialidade da pobreza expandiu-se vertiginosamente, a partir da visibilidade do processo de periferização (VALLADARES, 1991). Os moradores desses territórios passaram a construir seus ninhos nas periferias, em áreas invadidas e muitas vezes em locais humanamente insustentáveis. Onde estavam os projetos sociais? Onde estão? 
No contemporâneo, apesar de existir um programa social voltado à habitação para população carente, este programa é utilitário; ele ainda não dá cobertura a toda população. Além disso, instauraram-se a sedução pelo consumo nos últimos tempos e a desoneração dos automóveis. Somando-se a essas realidades, há a ruína do transporte coletivo, o excesso de carros nas ruas, os congestionamentos, o forte impacto na poluição do ar.

O fragmento de publicação a seguir, veiculado na Revista, mostra o conflito de interesses entre sociedade e lógica do sistema capitalista:

[...] interesse em lucrar se choca com a possibilidade de um sistema de transporte que atenda às necessidades da população" (NCAO2). O lucro é a alma do transporte […] sempre colocando o lucro das empresas acima de tudo. (NCA12).

O interesse é lucrar. O transporte coletivo público de qualidade e gratuito para todos não é prioridade. Não será prioridade de nenhum governo, enquanto o interesse ainda for o lucro; enquanto a prioridade de investimentos for para o transporte individual como as obras de infraestruturas dedicadas à circulação de automóveis. Essa realidade é um verdadeiro assalto aos cofres públicos; guarda ligação com a expansão do mercado imobiliário, de montadoras e concessionárias de veículos, além, é claro, com o tão exaustivamente posto, financiamento de campanhas (RIBEIRO, 2013). Ela não guarda qualquer ligação com a racionalidade ética, de uma ética pública, em que o poder está a serviço não de elites, mas do Estado; em que o sentido da ação está nos valores coletivos eleitos pelo Estado para prover mobilidade urbana digna para todos (NABUCO, 2017).

A Revista Caros Amigos também noticiou:

[...] o movimento visa lutar para a construção do programa de Passe Livre a Todos. Para isso, justificam que seria necessário que os mais ricos fossem taxados, para tal permissão, colocando em cheque a estrutura urbanística/capitalista brasileira [...] os sistemas midiáticos hegemônicos são vendidos aos governos, é a forma de opressão oficial (NCAO4) [...] a grande mídia (TVs, rádios e a grande maioria dos jornais), infelizmente esses órgãos estão a cada dia criando um fosso entre suas visões e as visões dos manifestantes que ganham as ruas do Brasil [...] há também uma cegueira para motivos básicos que inspiram tais manifestações. (NCAO5).

Aponta-se, no fragmento anterior, para a histórica ausência de regras do sistema tributário brasileiro (BERLINGUER, 2000). Na perspectiva da equidade, princípio vital em qualquer sistema tributário, "a contribuição dos cidadãos para o financiamento do Estado deve ser compatível com a sua capacidade econômica”. No entanto, estudo intitulado “Tributação, Previdência e Assistência Sociais: impactos distributivos", revelou que o sistema tributário brasileiro transita em direção contrária: os "10\% mais pobres da população brasileira destinam 32,8\% da sua - pouca - renda para o pagamento de tributos, enquanto que para os $10 \%$ mais ricos, o ônus estimado é de $22,7 \%$ da renda" (BRASIL, 2009, p. 23). O texto "Simplificando o Brasil: propostas de reforma na relação econômica do governo com o setor privado”, por sua vez, que utilizou o salário mínimo como unidade de referência para classificar os níveis de renda, sinalizou um vazio de progressividade: as famílias que ganham até dois salários-mínimos pagam $48,8 \%$ da sua renda em tributos; as que ganham mais de 30 salários-mínimos, cerca de 26,3\% (BRASIL, 2009).

Outra questão veiculada na Caros Amigos, implicada na defesa do SUS, em sua dimensão sustentabilidade, diz respeito à ênfase dada ao discurso contra a corrupção na segunda fase das manifestações, quando a questão primordial está noutro lugar, visivelmente específico: 
[...] o problema é o sistema capitalista em si, não a sua corrup̧̧ão em particular […] a consciência de que a forma institucionalizada de democracia multipartidária representativa não é suficiente para combater os excessos capitalistas, ou seja, que a democracia tem de ser reinventada. (NCAO6).

O cenário mundial contemporâneo tem se caracterizado por um conjunto de incertezas e mudanças nos padrões que estruturaram a modernidade. A incapacidade de o modelo multipartidário de democracia representativa reunir condições para dar respostas aos anseios e às necessidades dos cidadãos é uma de suas interfaces. No Brasil, este fato pode ser abordado a partir do histórico descaso com que a sociedade política, em senso estrito, trata os instrumentos participativos conquistados em 1988, o que em algum momento poderá impulsionar a politização efetiva da sociedade civil ou a sua despolitização.

Na dinâmica capitalista, o modelo de democracia representativa confere supremacia às ações reformistas em detrimento das emancipatórias, concebe sociedade civil como um ente formado por organizações apartadas de e em oposição ao Estado e sociedade política como aparato institucional de governo. Neste texto, de ideologia neoliberal, a atualização da análise gramsciana de Estado parece oportuna (TESSAROLO; KROHLING, 2011).

A compreensão gramsciana de sociedade civil não está descolada de uma perspectiva dialética com relação à sociedade política: a composição geral de Estado se dá na interpenetração de ambas as sociedades. Separando-as para fins heurísticos, Gramsci apontou que a sociedade política corresponde aos aparelhos estatais de coerção e a sociedade civil corresponde aos aparelhos privados de hegemonia. Em outras palavras, a sociedade política é formada pelos mecanismos com os quais as classes dominantes exercem seu domínio coercivo mediante o uso do aparato burocrático executivo e forças de repressão militar e policial, e a sociedade civil é composta pelos organismos sociais privados. Privados porque voluntários, independentes, persuasivos, responsáveis pela formulação e circulação das diferentes ideologias nas mais variadas esferas: políticas, econômicas, culturais, educacionais, religiosas ou sociais. As sociedades capitalistas, por exemplo, são organismos privados de hegemonia (FONTANA, 2003; GRAMSCI, 2007).

A busca pela hegemonia deste Estado implica a conquista de uma democracia intransigente, norteada pela disposição em transformar profundamente a estrutura e a superestrutura, o que dependerá das relações sociais de forças do momento histórico. Vivem-se tempos difíceis e que podem ainda piorar, mas não há tempo para análises simplistas e respostas fáceis; o caminho para o futuro precisa ser construído pelo conjunto da sociedade brasileira, em um grande pacto e com um amplo diálogo, o que só poderá ser feito nos marcos de outro projeto civilizatório, a partir de uma sociedade intransigentemente democrática (SIMIONATTO, 2002). O parágrafo anterior indica a necessidade de se repensar a democracia, em um movimento que, antes de tudo, tenha como objetivo esta sociedade.

Em resposta ao movimento de manifestações de 2013, o Estado brasileiro viu-se na obrigação de dar resposta à sociedade. Lançou um pacto nacional, estruturado por cinco pontos principais de ação - responsabilidade fiscal, reforma política, saúde, educação e transporte -, que seria desenvolvido conjuntamente com os 27 Estados da Federação(BRASIL, 2015).

Como o estopim das manifestações foi referente aos transportes públicos, a resposta inicial foi neste setor: o governo federal prometeu investimentos de até $\mathrm{R} \$ 50$ bilhões de reais para melhoria na mobilidade urbana. No entanto, os dados do Portal da Transparência mostram que os 
investimentos ficaram na casa $\operatorname{dos} \mathrm{R} \$ 8$ bilhões. Para a educação, foi aprovado o Plano Nacional de Educação, que contêm 20 metas a serem alcançadas, até 2024, conjuntamente entre União, Estados e municípios (MARICATO et al., 2013).

E em defesa do SUS? Algum desdobramento? Sim, a criação do Programa Mais Médicos. No mês seguinte às manifestações, a Presidente Dilma Rousseff editou a Medida Provisória $\mathrm{n}^{\circ}$ 62 1, de 8 de julho de 2013, criando o Programa Mais Médicos (PMM) (BRASIL, 2013a). Três meses depois, o Congresso Nacional aprovou e a Presidente sancionou a Lei ${ }^{\circ} 12.871$, instituindo o PMM, para garantir, dentre outros, atenção médica na atenção básica de Brasis marginalizados e invisíveis à medicina liberal, por meio de oferta de curso de especialização na atenção básica, bolsa-formação e ajuda de custo (BRASIL, 2013b).

Quanto à responsabilidade fiscal, o governo assumiu o compromisso de garantir a estabilidade da economia e o controle da inflação, tendo como estratégia o combate à corrupção e ao mau uso dos recursos públicos. E, por fim, a mais reivindicada, a reforma política, que não passou de uma minirreforma eleitoral, sem produção de mudanças de fundo no sistema eleitoral brasileiro.

No que tange à dimensão comunicativa das manifestações, o que elas sinalizaram? Com base na análise empreendida, foi possível concebê-las como uma tecnologia social, na medida em que elas atuaram como uma alternativa de produção e difusão de saberes populares, por grupos subalternizados pelo projeto moderno de organização política. Em seu sentido geral, a expressão "tecnologia social”:

[...] refere-se à criação e utilização de conhecimentos por populações duplamente desfavorecidas (por falta de acesso ao conhecimento científico moderno e por perda das condições mais favoráveis à reprodução de seu conhecimento tradicional), de modo a promover [...] o fortalecimento cultural e político das comunidades. (GARCIA, 2014, p. 251).

O estudo reafirmou que a garantia do direito à saúde depende, intimamente, da criação de políticas sociais, com definição de investimentos econômicos que garantam, de fato, a concretização das políticas. Para que a saúde conquistada constitucionalmente seja materializada, há necessidade, sobretudo, de o Estado alçar voos em direção à distribuição equitativa da riqueza do país, para fins de composição de um projeto de sociedade na qual todos possam adquirir, em sua significação máxima, o sentido da cidadania. Experimentando a beleza da condição humana e reconhecendo que um dos maiores problemas que agridem a humanidade é a injustiça, condição que priva as pessoas de dignidade, isto é, priva-as do tão caro meio de alcançar saúde (DINIZ, 2009).

\section{CONSIDERAÇÕES}

A análise das manifestações, de junho de 2013, sob a ótica da Revista Caros Amigos, realizada no recorte temporal entre 01/06/2013 e 31/10/2013, permitiu uma melhor compreensão daquele momento histórico e do contexto em que as manifestações ocorreram. Com base na categoria "Da Saúde como Direito Social à Democracia como Direito à Saúde", a defesa do SUS foi expressa em termos de: a) transporte público gratuito e de qualidade para todos; b) investimentos na área de educação; c) investimentos na mobilidade urbana, com vistas à priorização de obras que beneficiem o transporte coletivo público; d) direito à cidade, ao lazer e à cultura; e) investimentos 
em estruturas públicas de saúde e em provimento médico; e f) reforma política. A concretização de tais reivindicações exige o fim da corrupção e uma ampla reforma política.

Concluiu-se que as manifestações de 2013 geraram desdobramentos em matéria de direitos sociais. O Plano Nacional de Educação foi instituído com metas para até 2024. O Programa Mais Médicos foi criado, garantindo atenção médica na atenção básica do SUS de Brasis desassistidos. A produção e a difusão de saberes e reconhecimentos populares produziram uma tecnologia social, pois viabilizaram os anseios de uma população que historicamente luta por seus direitos e busca a cada dia, em meio à opressão e ao sofrimento, fazer com que suas vozes sejam ouvidas e seus anseios atendidos nesta democracia representativa que, na grande maioria das vezes, representa a si mesma e aos seus interesses.

Caberá às organizações populares e aos movimentos sociais a busca pela democracia participativa e transformadora, pois a conquista de novos ventos e novos espaços está intimamente relacionada à ocupação de posições que permitam ao povo participar ativamente de decisões, seja no campo da política, no campo social ou econômico. As manifestações mostraram ainda que é necessário refletir (ética) para mudar criticamente (política) o modus operandi com o qual a sociedade brasileira está acostumada, pois eleger um representante a cada quatro anos não exime a responsabilidade de cada um nesse processo democrático diário. Fica a compreensão de que o Brasil requer um choque de cidadania, para defender um projeto justo de sociedade.

\section{REFERÊNCIAS}

BERLINGUER, G. Bioética quotidiana. Firenze: Giunti, 2000.

BOITO JÚNIOR, A. A natureza da crise política brasileira. Le Monde Diplomatique, v.104, n.1, p.1-7, 2016.

BRASIL. Ministério da Saúde. Programa Mais Médicos - dois anos: mais saúde para os brasileiros. Brasília: Ministério da Saúde, 2015.

BRASIL. Ministério da Saúde. Saúde pública quer levar mais médicos para áreas remotas do País. 2013a. Disponível em: <http://www.brasil.gov.br/governo/2013/06/saude-publica-quer-levar-maismedicos-para-areas-remotas-do-pais $>$. Acesso em: 10 jan. 2017.

BRASIL. Medida Provisória no 62 1, de 08 de julho de 2013. Institui o Programa Mais Médicos e dá outras providências. Diário Oficial da União, de 9 de julho de 2013 b.

BRASIL. Lei $\mathbf{n}^{\mathbf{0}} \mathbf{1 2 . 8 7 1}$ de 22 de outubro de 2013. Institui o Programa Mais Médicos, altera as Leis no 8.745 de 9 de dezembro de 1993, e no 6.932, de 7 de julho de 1981, e dá outras providências. Diário Oficial da União, de 23 de outubro de 2013 c.

BRASIL. Instituto de Pesquisa Econômica e Aplicada. Receita pública: Quem paga e como se gasta no Brasil. 2009. Disponível em: <http://ipea.gov.br/agencia/images/stories/PDFs/ comunicado/090630_ comunicadoipea22.pdf>. Acesso em: 07 jan. 2017.

BRASIL. Ministério da Saúde. Relatório Final da VIII Conferência Nacional de Saúde. 1986. Disponível em: <http://bvsms.saude.gov.br/bvs/publicacoes/8_conferencia_nacional_saude_relatorio_final.pdf>. Acesso em: 05 dez. 2016.

COMPARATO, F. K. Constituição de 1988: o direito e o avesso. 2016. Disponível em: < http:// 
diplomatique.org.br/constituicao-de-1988-o-direito-e-o-avesso/z. Acesso em: 05 dez. 2016.

COUTINHO, C. N. O Estado brasileiro: gênese, crise, alternativas. In: LIMA, J. C. F; NEVES, L. M. W (Org.). Fundamentos da educação escolar do Brasil contemporâneo. Rio de Janeiro: Fiocruz, 2007. p. 173-200.

DE MORAES, A. B. et al. As manifestações de junho de 2013, o processo de construção dos direitos de cidadania no Brasil e o direito à cidade. Revista de Direito da Cidade, v.7, n.1, p.71-90, 2015.

DINIZ, D. Assistência Farmacêutica do SUS. 2009. Disponível em: < http://www.stf.jus.br/portal/cms/ verTexto.asp? servico=processoAudienciaPublicaSaude\&pagina=Cronograma $>$. Acesso em: 10 jan. 2017.

FONTANA, B. Hegemonia e nova ordem mundial. In: COUTINHO, C. N; TEIXEIRA, A. P. (Org.) Ler

Gramsci e Entender a Realidade. Rio de Janeiro: Civilização Brasileira, 2003. p.113-125.

GARCIA, S. G. A tecnologia social como alternativa para a reorientação da economia. Estudos Avançados, v.28, n.82, p.251-275, 2014.

GONÇALvES, R. A. O papel das revistas Veja e Carta Capital na formação da opinião pública brasileira acerca das manifestações populares. Revista Anagrama, v.7, n.2, p.1-13, 2013.

GRAMSCI, A. Quaderni del carcere. 3.ed. Torino: Einaudi, 2007.

LIMA, R. C. G. S. et al. Tutoria acadêmica do Projeto Mais Médicos para o Brasil em Santa Catarina: perspectiva ético-política. Ciência e Saúde Coletiva, v.21, n.9, p.2797-2805, 2016.

LINCOLN, S. et al. Cidades rebeldes: as jornadas de junho. São Paulo: Boitempo, 2013.

MANACORDA, M. A. Antonio Gramsci: l'alternativa pedagogica. Roma: Riuniti, 2012.

MARICATO, H. et al. Cidades rebeldes: Passe Livre e as manifestações que tomaram as ruas do Brasil. São Paulo: Boitempo, 2013.

NABUCO, A. Entrevista com Olívio Dutra: Voo livre no PT. Caros Amigos, v.238, p.18-23, 2017.

PIMENTEL, A. O método da análise documental: seu uso numa pesquisa historiográfica. Cadernos de Pesquisa, n.114, p.179-195, 2001.

POCHMANN, M. Nova classe média?. São Paulo: Boitempo, 2012.

RIBEIRO, G. Posições: as manifestações de junho de 2013 e a realização da política no Brasil urbano do século XXI. Revista Continentes (UFRRJ), v.2, n.3, p.116-120, 2013.

SCHERER-WARREN, I. Manifestações de Rua no Brasil 2013: encontros e desencontros na política. Caderno CRH, v.27, n.71, p.417-429, 2014.

SEMERARO, G. A "utopia” do Estado Ético em Gramsci e nos movimentos populares. Revista de Educação Pública, v.29, n.44, p.465-480, 2011.

SIMIELLI, E. R. Polímeros. Caros Amigos, v.7, n.4, p.1-3, 1997.

SIMIONATTO, I. Cadernos do cárcere. Revista Brasileira de Ciências Sociais, v.17, n.48, p.212-215, 2002.

SPINK, M. J. (Org.). Práticas discursivas e produção de sentidos no cotidiano: aproximações teóricas e metodológicas. Rio de Janeiro: Centro Edelstein, 2013. 
SPINK, M. J. Linguagem e produção de sentidos no cotidiano. Porto Alegre: EDIPUCRS, 2014.

TESSAROLO, E. M.; KROHLING, A. Democracia participativa no estado do Espírito Santo: (des) articulações e limites na atuação do Conselho Popular de Vitória. Anais do Seminário Nacional da Pósgraduação em Ciências Sociais. Espírito Santo: UFES, 2011.

VALLADARES, L. P. Cem anos pensando a pobreza (urbana) no Brasil. In: BOSCHI, R. R. (Org.) Corporativismo e Desigualdade: a construção do espaço público no Brasil. Rio de Janeiro: Rio Fundo, 1991. p. 81-112. 